\title{
Retraction Notice: R.S. Orlov, Genesis of the Planet Earth, Evolving Trends in Engineering and Technology, Vol. 5, pp. 1-10, 2015.
}

\section{Editorial office of International Journal of Engineering and Technologies}

\author{
Seestrasse 24c, CH-8806 Bach, Switzerland \\ ijet@scipress.com
}

This article has been retracted at the request of the Publisher's representatives.

The manuscript [1] is a duplicate of another publication by the same author [2]. The paper was published in the Evolving Trends in Engineering and Technology nearly four months after the publication in the Global Journal of Science Frontier Research. Our policy is to consider only original, unpublished articles that are not under review by any other journal. We are strictly committed to ensuring the high quality standards and ethics in publication. Thus, in line with the Retraction Guidelines of the Committee on Publication Ethics the article is retracted based on the evidence of the duplicate publication.

The author has been informed about the decision to retract the article [1]. Thus, the paper has been declared retracted and labelled accordingly.

\section{References}

[1] R.S. Orlov, Genesis of the Planet Earth, Evolving Trends in Engineering and Technology. 5 (2015) 1-10. DOI: 10.18052/www.scipress.com/ETET.5.1.

[2] S. Orlov, Genesis of the Planet Earth, Global Journal of Science Frontier Research. 14(6) (2014). 